\title{
Quality Control of Juices Produced in Democratic Republic of Congo and Marketed in Lubumbashi
}

\author{
Isabelle Kasongo Omba ${ }^{1,2}$, Criss Koba Mjumbe ${ }^{1 *}$, Guyslain Mashini Ngongo, \\ Oscar Luboya Numbi ${ }^{1}$
}

${ }^{1}$ Department of Public Health, Faculty of Medicine, University of Lubumbashi, Lubumbashi, Democratic Republic of the Congo ${ }^{2}$ Microbiology Laboratory, Congolese Office of Control COC, Lubumbashi City, Democratic Republic of Congo

Email: *cryss_koba25@yahoo.fr

How to cite this paper: Omba, I.K., Mjumbe, C.K., Ngongo, G.M. and Numbi, O.L. (2020) Quality Control of Juices Produced in Democratic Republic of Congo and Marketed in Lubumbashi. Food and Nutrition Sciences, 11, 255-261.

https://doi.org/10.4236/fns.2020.114019

Received: January 30, 2020

Accepted: April 12, 2020

Published: April 15, 2020

Copyright $\odot 2020$ by author(s) and Scientific Research Publishing Inc. This work is licensed under the Creative Commons Attribution International License (CC BY 4.0).

http://creativecommons.org/licenses/by/4.0/ (c) (i) Open Access

\begin{abstract}
The consumption of juice has increased sharply in recent years in Lubumbashi. The objective of this study was to determine the standards applicable to the types of juice for domestic consumption in Lubumbashi. A descriptive cross-sectional study on quality control (QC) of ten brands of juice selected from around thirty listed on the Lubumbashi markets focused on the determination of different physico-chemical and microbiological parameters. Physical analysis of the juices was carried out in the laboratory of the Congolese Office of Control (OCC) in February 2019. It appears that five samples, or 25\%, have a density lower than the ISO 9001 standard. All the samples have a Brix Degree in accordance with French standards applicable by the Congolese control office. The chemical analysis shows that 4 samples, or $20 \%$, have a $\mathrm{pH}<4$, therefore higher than the prescribed standards. As for the titratable acidity and the formaldehyde index, all the samples have values within normal limits. On the other hand, the glucose level of all the samples is abnormally high $(\geq 40 \mathrm{~g} / \mathrm{L})$. The sucrose level of $50 \%$ of the samples is normal $(\geq 80 \mathrm{~g} / \mathrm{L})$. Microbiological analysis revealed that certain juices were without preservatives and harbored aerobic mesophilic germs (10\%), lactic bacteria $(20 \%)$ yeasts and molds (10\%). It is urgent that the public authorities bring all the producers to respect the standards in order to protect the health of the populations.
\end{abstract}

\section{Keywords}

Fruit Juice, Quality Control, Lubumbashi/Democratic Republic of Congo

\section{Introduction}

Juice is a liquid extracted from the pulp, from the flesh of certain fruits or vege- 
tables; drink is constituted by this liquid. Several products can be made from the pressed fruit: pure fruit juice, fruit juice, fruit nectar, fruit drinks. The soluble dry matter content of the finished product ranges from $5 \%$ to $15 \%$. Thanks to the seasonality of the various varieties, the company can obtain different kinds of fruit all year round [1]. Juice is one of the most widely consumed fruit drinks in the world in general and in Africa in particular [2]. It is a drink consumed for its refreshing and nutritional qualities (vitamins). The pleasant color of the juice, the accessible cost and its taste make it one of the drinks not only accessible but also more appreciated in our Country. There is a large market for this product, but it remains underdeveloped and unregulated for the time being. Zambia, Zimbabwe and South Africa export a few thousand hectoliters (hl) per year. The high production cost is intended for the juice to an urban clientele with strong purchasing power [3]. The market can be developed towards consumers with average incomes by the marketing of small packages (small doses of 10,15 cl), of affordable unit price. The level of requirement of the standards imposes a perfectly mastered know-how: impeccable bacteriological quality, appropriate packaging, attractive presentation, regularity of supply, satisfactory organoleptic qualities. The juice is more and more consumed by the population of Lubumbashi. But the insufficiency of reliable data on the quality of this product, and the absence of a quality assurance system within the structures producing these juices in the Congo lead us to question the quality of the juices produced locally and even of the juice from other countries. It is to answer this question that we set out to assess the physico-chemical and microbiological quality of the juices produced in Haut-Katanga and marketed in Lubumbashi in order to assess the risks linked to the consumption of these products. Quality control (QC) is in fact an operation intended to determine, with appropriate means, whether or not the controlled product conforms to its predefined specifications or requirements and includes a decision of acceptance, rejection or retouching. It comes at the end of production or result to see if the product produced conforms to predefined specifications and standards [4] [5] [6]. This could constitute a guarantee for the manufacturer and the consumer. The general objective of this work was therefore to assess the overall quality of the juices produced in Lubumbashi.

\section{Materials and Method of Study}

\section{Study Materials}

They are made up of 10 different brands of fruit juice selected without the producers' consent, among the thirty identified and produced in Haut Katanga. Physico-chemical and microbiological tests were carried out at the Microbiology Laboratory of the Congolese controloffice in Lubumbashi in March 2019.

\section{- List of fruit juices collected}

Table 1 indicates the list of (codified) fruit juices collected as well as the place of collection.

\section{- Confidentiality}


Table 1. List of pineapple juices collected.

\begin{tabular}{ccc}
\hline Codified sample & Place of production & MA: Marketing Authorization \\
\hline $\mathrm{Aa}$ & Lubumbashi & Yes \\
$\mathrm{Bb}$ & Lubumbashi & Yes \\
$\mathrm{Ww}$ & Lubumbashi & Yes \\
$\mathrm{Zz}$ & Others & Yes \\
$\mathrm{Cc}$ & Lubumbashi & Yes \\
$\mathrm{Dd}$ & Lubumbashi & Yes \\
$\mathrm{Rr}$ & Lubumbashi & No \\
$\mathrm{Qq}$ & others & Yes \\
$\mathrm{Ee}$ & Lubumbashi & Yes \\
$\mathrm{Ff}$ & Lubumbashi & Yes \\
\hline
\end{tabular}

All samples are coded and do not bear the name of the manufacturer concerned.

\section{- Different activities carried out}

For strategic reasons, the work plan (Figure 1) has been adopted. In fact, the flow diagram in Figure 1 shows the different stages of quality control (QC) of the samples after the research protocol as well as all of the tests carried out.

\section{- Specific procedures}

Regarding the study of each sample collected, we went by marking the sample of three types by brand indicated on the list of fruit juices in suite, they were coded in I, II and III according to the distribution by type and by brand of juice.

\section{Results}

\subsection{Situation of the Environment}

This study aims to carry out an analysis of the situation in Lubumbashi in terms of the quality of the fruit juices produced in Haut Katanga and marketed in Lubumbashi included ten (10) different brands of fruit juice out of the 30 identified. These juices presented in different presentations come from different production places: Lubumbashi (8/10 or $80 \%)$ and outside Lubumbashi (2/10 or $20 \%)$.

\subsection{Visual Identifications}

From the analysis of the results of the visual identification (Table 2), it emerges that the market for the marketing of fruit juices produced in Haut Katanga still covers some illegal practices: 1) Sale of fruit juices without authorization for placing on the market (20\% of the juices inspected), 2) Sale of juice without indication of the expiry date (expiry date) (10\% of the juices inspected).

\subsection{Physico-Chemical and Microbiological Tests}

It appears from Table 3, based on the analysis of the physical characteristic test 


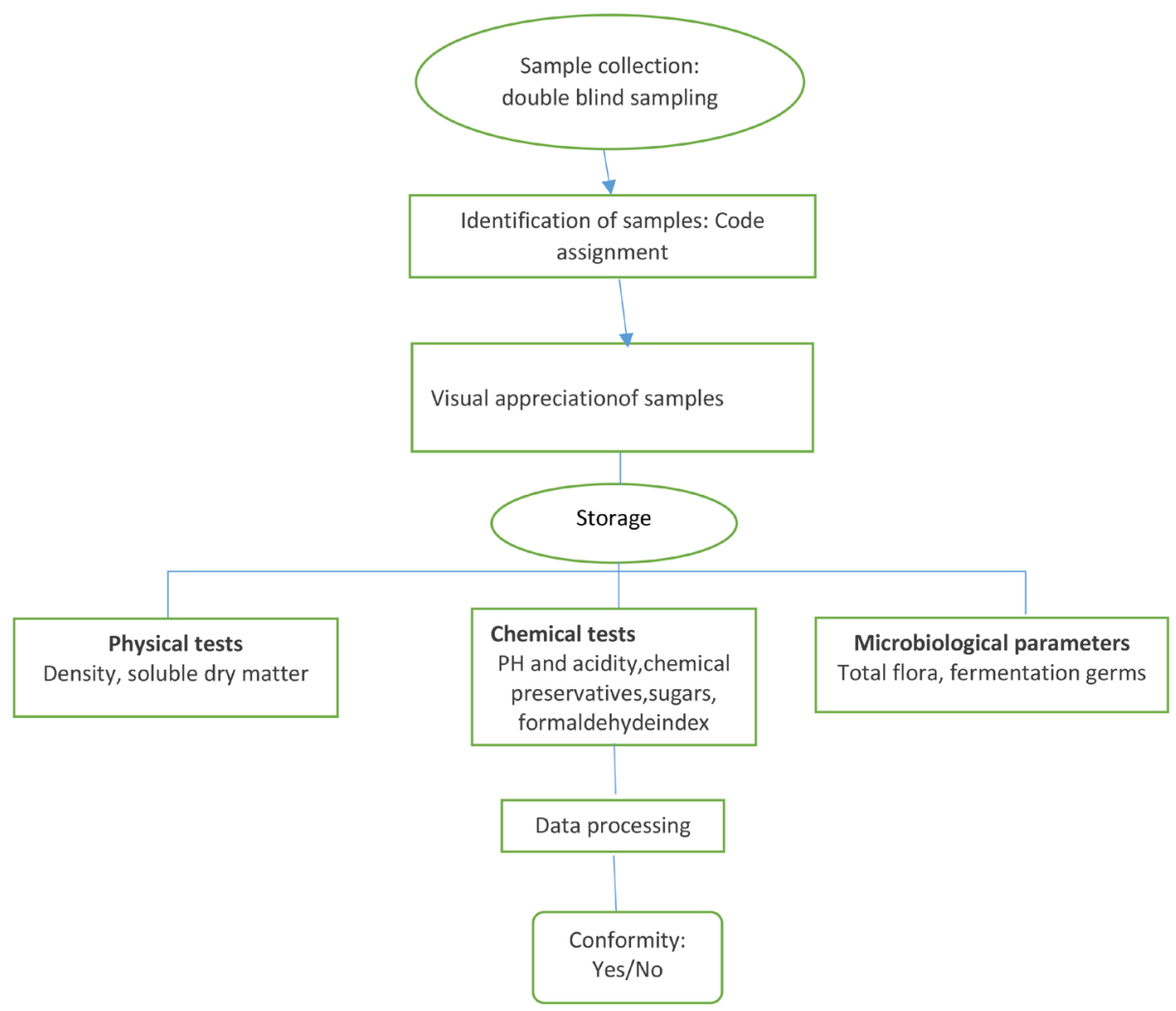

Figure 1. Different stages of quality control of fruit juices.

Table 2. Results of visual identification.

\begin{tabular}{cccc}
\hline Party inspected & Items inspected & Observation & Frequency of non-compliance \\
\hline Commercialname & Absent & & $0 \%$ \\
Primary packaging Manufacturer's name and address & This & & $0 \%$ \\
Expiration date & Absent & $1 / 10$ is & $10 \%$ \\
MA & Absent & $2 / 10$ is & $20 \%$ \\
\hline
\end{tabular}

MA: Marketing authorization.

Table 3. Results of physico-chemical and microbiological tests.

\begin{tabular}{|c|c|c|c|c|c|}
\hline \multirow{2}{*}{ Tests } & \multirow{2}{*}{ Main tests carried out } & \multirow{2}{*}{ Number of samples analyzed } & Compliance & ompliance & \multirow{2}{*}{ Normal Value } \\
\hline & & & \multicolumn{2}{|c|}{ Compliance/no compliance } & \\
\hline Determination of & Relative density & 20 & $18(90 \%)$ & $3(10 \%)$ & $>1.045$ \\
\hline \multirow[t]{3}{*}{ physical characteristics } & BrixDegree & 20 & $20(100 \%)$ & $0(0 \%)$ & $>11.2$ Brix \\
\hline & $\mathrm{pH}$ & 20 & $16(80 \%)$ & $4(20 \%)$ & $<4$ \\
\hline & Titratable acidity & 20 & $20(100 \%)$ & $0(0 \%)$ & $50-180 \mathrm{mmol} / \mathrm{L}$ \\
\hline Determination of & Formalin index & 20 & $20(100 \%)$ & $0(0 \%)$ & $8-20 \mathrm{ml}$ de $\mathrm{NaOH}$ \\
\hline \multirow[t]{3}{*}{ chemical characteristics } & Glucose content & 20 & $7(35 \%)$ & $13(65 \%)$ & $15-40 \mathrm{~g} / \mathrm{L}$ \\
\hline & Search for curators & 20 & $11(55 \%)$ & $9(45 \%)$ & Présence \\
\hline & Sucrose level & 20 & $10(50 \%)$ & $10(50 \%)$ & $40-80 \mathrm{~g} / \mathrm{L}$ \\
\hline
\end{tabular}


data relating to the relative density, that 2 juices are non-compliant $(<1.045)$ and that all $100 \%$ have a Brix degree in the standards. With regard to the analysis of the test data for the chemical characteristics mentioned in the table, the analysis of the results relating to the $\mathrm{pH}$ reveals that 4 juices or (20\%) are non-compliant $(\mathrm{pH}>4)$; all had titratable acidity and the formalin index in standards 20 (100\%). The glucose content and the search for preservatives met the standards respectively at $[7(35 \%)$ and $11(55 \%)]$ and the sucrose level respected the standards by half $10(50 \%)$.

\subsection{Microbiological Analysis}

There is a strong contamination (20\%) of the juices by lactic acid bacteria (2000 to $4800 \mathrm{CFU} / \mathrm{mL}$ ). $10 \%$ of the juices analyzed in our study have a GAM $>1.00$ $\mathrm{UFC} / \mathrm{mL}$ content. $10 \%$ of the juices analyzed have a high contamination with YM (Table 4).

\section{Discussion}

All juices underwent a visual appreciation test. Table 2 represents the results of the visual identification carried out on all of these collected juices. The fact that certain statements are missing does not guarantee that there is no risk to the health of consumers as required by food safety standards. Therefore, different physico-chemical tests have been applied to these juices: these are tests to determine: density, soluble dry matter, titratable acidity, formaldehyde index, sugar level, preservatives chemicals, pH. Several standards have been used: ISO 9001 standard, NFV 76-008, NFV 78-008, Codex standard STAN 85-1981, STAN 247-2005 [4] [5] [6] [7]. The microbiological parameters were studied according to the recommendations of standardization and the work of Herigstad et al. These parameters are as follows: total flora, fermentation germs (lactic acid bacteria, yeasts and molds) [8] [9]. Let's say that even if a non-compliance (density $<$ normal) to the density tests does not necessarily mean the presence of a risk for the patient's health, it is however inconvenient to dilute the juice with water or other solution during production to maximize gains. This poses the problem of loss of active nutrients to be administered. Given that the physical tests on fruit juices are essential steps before being able to release the batches, the problem of the quality of the marketed juices then arises. Also, it is important to have the equipment that meets the needs: compliant with standards (NF for example),

Table 4. Results of the microbiological analysis.

\begin{tabular}{ccccc}
\hline \multirow{2}{*}{ Results } & & \multicolumn{3}{c}{ Germs searched } \\
\cline { 3 - 5 } & & TMAG & LB & YM \\
\hline \multirow{3}{*}{ Conformity } & Nocompliant & $10 \%$ & $20 \%$ & $10 \%$ \\
& Compliant & $90 \%$ & $80 \%$ & $90 \%$ \\
& Standard & $<1.00 \mathrm{UFC} / \mathrm{mL}$ & $<700 \mathrm{UFC} / \mathrm{mL}$ & $<300 \mathrm{UFC} / \mathrm{Ml}$ \\
\hline
\end{tabular}

TMAG: Total mesophilic aerobic germs, LB: Lactic bacteria, YM: Yeasts and molds. 
robust, and reliable to control the juices produced. The large proportion of excessively diluted juice (15\%) that did not pass the density tests could confirm this statement: The fruit juices produced are not necessarily produced in large establishments [10]. Analysis of the results relating to $\mathrm{pH}$ reveals that 4 juices are non-compliant $(\mathrm{pH}>4)$. Several reasons could explain this state of affairs: 1$)$ dilution of the juice with water during production and 2) the use of overripe fruits, since an increase in the sugar level could decrease the content of acidity of juices. Indeed a $\mathrm{pH}$ higher than 4 does not always guarantee a long-term conservation of the juices and the microbiological quality of these juices. This constitutes a risk to the health of populations (risk of food poisoning). According to ISO 9001 NF V76-008 [4], the content of glucose in fruit juices must be between $15-40 \mathrm{~g} / \mathrm{L}$. All the juices analyzed have contents $>$ the norm (rate varying between 48.78 and $99.05 \mathrm{~g} / \mathrm{L}$ ). This rise in glucose levels could be explained by: 1) hydrolysis of sucrose during storage, 2) enzymatic hydrolysis of maltose to glucose and 3) advanced maturity of the fruits used. The more ripe the fruit, the more simple sugars such as glucose and fructose are released. According to Guiraud et al. [10], a high number of GAMs often reflects contamination of raw materials, poor production conditions (unhealthy and poorly maintained premises, lack of personal hygiene) and conservation. This is also confirmed by the high contamination (20\%) of the juices by lactic acid bacteria (2000 to 4800 $\mathrm{CFU} / \mathrm{mL}$ ). In addition to improper pasteurization, packaging leaks could be blamed. All this challenges the authorities in charge of food regulation that it is necessary to be extra vigilant because the health risks for consumers are enormous. Our study also reveals, from the analysis of all the results (data mentioned in Tables 1-4) that juices which did not pass the quality control tests were also found among those which had a Marketing Authorization than those who did not. Having MAID is therefore not a guarantee. This calls on the authorities in charge of the regulation that it is necessary to redouble vigilance because the control of the circuit of foodstuffs (manufacture, distribution, sale) must guarantee the quality and the harmlessness of these. In the present study, we did not carry out research on pathogenic microorganisms, because the $\mathrm{pH}$ of the different juices may not allow the survival of such germs in this medium.

\section{Conclusion}

The present study on the evaluation of the quality of fruit juice produced and marketed in Lubumbashi has identified 30 different brands of fruit juice. For strategic and temporal reasons, 10 different brands from different producers were chosen for the quality assessment using several benchmarks (ISO 9001 standards). These juices were produced in Lubumbashi (80\%) and the market for the marketing of the fruit juices produced still covers certain illegal practices. In relation to the relative density, the juices with a value of $(<1.045)$ were non-conforming whereas (100\%) of the juices had a Brix degree in the standards. The analysis of the results relating to the $\mathrm{pH}$ revealed $20 \%$ is non-compliant $(\mathrm{pH}>$ 
4). There is a strong contamination (20\%) of the juices by lactic acid bacteria (2000 to $4800 \mathrm{CFU} / \mathrm{mL}$ ). $10 \%$ of the juices are analyzed in our study on a content of GAM $>1.00 \mathrm{UFC} / \mathrm{mL}$. It is important to see which ones pose a huge risk to consumers. A larger study should be carried out according to the same rules of good practice for a more complete analysis of the situation.

\section{Authors' Contribution}

All the authors of this article have made a significant contribution to the design, implementation and/or analysis and interpretation of the data, to the development of the article and to the critical review of its intellectual content.

\section{Conflicts of Interest}

The authors do not declare any conflict of interest.

\section{References}

[1] François, M. (1995) Transforming tropical fruits. Le Point sur les technologies, Paris, $224 \mathrm{p}$.

[2] Broutin, C. and Sokona, K. (1994) Preparing and Selling Traditional Drinks: Experiences and Procedures. Practical Guide, Paris, $94 \mathrm{p}$.

[3] ISO 9001 (2008) Quality Management Systems-Requirements.

[4] AFNOR (1995) French Standard NF V 76-008: Pineapple Juice. 11 p.

[5] CODEX STAN 85-1981 (1981) Codex Standard for Pineapple Juice Preserved Exclusively by Physical Process.

[6] CODEX STAN 247-2005 (2005) Codex General Standard for Fruit Juices and Nectars.

[7] AFNOR (1994) French Standard NF en 1131: Determination of the Formaldehyde Index. 2.

[8] Herigstad, B., Hamilton, M. and Heersink, J. (2001) How to Optimize the Drop Plate Method for Enumerating Bacteria. Journal of Microbiological Methods, 44, 123. https://doi.org/10.1016/S0167-7012(00)00241-4

[9] AFNOR (2002) Food Microbiology. Routine Methods and Evaluation of an Alternative Method. Volume 2, 8th Edition, 8-9.

[10] Guiraud, J. and Galzy, P. (1980) Microbiological Analysis in the Food Industries. The New Factory, Paris, 236. 